\title{
Measurement of Dissolved Oxygen as a Determination of Media Equilibrium During Dissolution Testing
}

\author{
Thomas Curley, Richard Forsyth ${ }^{1}$, Susan Sun, Kyle Fliszar, Mitch Colletto and Gregory P. Martin \\ Pharmaceutical Analysis \& Control, PR\&D, Merck \& Co. \\ West Point, PA, USA.
}

\begin{abstract}
Scientists have known for years that deaeration of aqueous dissolution media can affect the dissolution rate of solid dosage forms. Several methods have been developed to accomplish deaeration, but the industry standard has been the USP method, using heat, vacuum and filtering. Alternate methods of deaeration may be considered comparable to the USP method by passing the USP Apparatus Suitability Tests, using USP Prednisone and Salicylic Acid calibrator tablets. Closer examination of this procedure, however, indicated that additional tests of deaeration levels were warranted. The USP Apparatus Suitability Tests do not measure to any degree the actual amount of dissolved air present.

The use of some techniques may actually deaerate dissolution media to too low a level. Media with low levels of dissolved air absorbed air, and saturated media released dissolved air, until equilibrium was achieved. It was shown that dissolved air in dissolution media adjusted to achieve equilibrium. Acceptable results for the Apparatus Suitability Tests should be combined with measurement of the dissolved oxygen to assure that dissolution testing is conducted on a consistent basis.

Through experiments, it was established that a level of dissolved oxygen within a range of $4-7 \mathrm{mg} / \mathrm{L}$ produced an equilibrium effect in regard to dissolved air in the media, such that no appreciable change occurred during the dissolution process. USP-equivalent media should only be produced by a means that results in near equilibrium of both temperature \& dissolved air.
\end{abstract}

\section{Introduction}

$\mathrm{T}$ he scientific community has accepted that dissolved air in dissolution media can affect the dissolution rate of solid dose units.

Several methods have been developed to accomplish deaeration, but the industry standard has been the USP method, using heat, vacuum and filtering (1). Alternate methods of deaeration were declared comparable to the USP method by virtue of passing the USP Apparatus Suitability Tests, using USP Prednisone and Salicylic Acid calibrator tablets. Closer examination of this procedure, however, indicated that additional tests of deaeration levels were warranted. The USP Apparatus Suitability Tests, while indicating apparatus suitability, did not measure to any degree the actual amount of dissolved air present. Oxygen, being approximately $20 \%$ of air, was easily measured using available dissolved oxygen meters. The measurement of dissolved oxygen allowed a quantitative means to confirm comparability to USPdeaerated media.

The use of some deaeration techniques may actually deaerate dissolution media to too low a

${ }^{1}$ To whom all correspondence should be addressed, email: Richard_forsyth@merck.com level. It has been theorized that deaeration to too low a level, such as by vacuum/sonication deaeration, may actually create a disturbance during the dissolution process (2). Dissolved air in dissolution media adjusted to achieve equilibrium. Media with low levels of dissolved air absorbed air until equilibrium was achieved. Conversely, saturated media released dissolved air, until equilibrium was achieved.

Since deaeration is basically the removal of dissolved air in the media, it seemed most appropriate to measure a major component of that dissolved air. Dissolved oxygen has long been measured in the waste water treatment industry, and several portable oxygen meters were available, with demonstrated ease of use and reliability in reproducing results. The level of dissolved oxygen, which could be measured, was a direct relation to the amount of dissolved air, or deaeration of the dissolution media. This provided a measurable means of comparing methods of deaeration to the USP method. In addition, the amount of deaeration and time required to achieve the optimal level of deaeration were also determined for each method in use.

The objectives of this project were to develop a means of accurately measuring the deaeration of 
dissolution media; to determine a measurable equilibrium for dissolution media used at $37^{\circ} \mathrm{C}$; and to determine the most efficient means of producing equilibrated media ready for use. These experiments resulted in potential guidelines for deaeration of dissolution media for USP dissolution.

\section{Experimental}

Methods of deaeration employed for these experiments:

a. USP Method - heat to $41{ }^{\circ} \mathrm{C}$ while stirring. Filter through $0.45-\mu \mathrm{m}$ filter under vacuum and stir $5 \mathrm{~min}$ utes under vacuum. Cool before use (1).

b. Gas permeable membrane deaeration apparatus consisting of a water heating bath and Erweka Dissofil ${ }^{T M}$ deaeration unit

c. Helium sparge at $37^{\circ} \mathrm{C}$ for $1-20$ minutes

d. Sonication/vacuum

e. Heat to $37^{\circ} \mathrm{C}$ and stir (on hot plate/stirrer)

f. Stir at room temperature (RT) by magnetic stirrer

g. Heat and stir in USP Dissolution Apparatus 2, Paddle at $50 \mathrm{rpm}, 37^{\circ} \mathrm{C}$

Deaeration was measured by an Orion Model \#830 Dissolved Oxygen meter. The meter was calibrated electronically according to the manufacturer's specifications.

Using Apparatus 2, Paddle, at 50 rpm, six dissolution vessels were filled with $900 \mathrm{~mL}$ of deionized water. Two vessels were helium sparged for 20 minutes, two vessels were filled with gas permeable membrane water, and two vessels contained untreated deionized water. All six were measured for dissolved oxygen initially and after 24 hours of stirring at $50 \mathrm{rpm}$ at $37^{\circ} \mathrm{C}$. At this point it was determined through measurement that no further changes in dissolved oxygen were likely to occur.

The experiment was repeated, taking measurements initially and periodically up to 5.5 hours. By the 5.5 hour time point, all vessels were found to have dissolved oxygen within $0.1 \mathrm{mg} / \mathrm{L}$ of the 24 hour test, indicating that equilibrium had been reached by 5.5 hours.

To determine the effect of stirring alone, 4 liters of untreated deionized water were stirred at ambient room temperature. Dissolved oxygen was measured at initial, 30 minutes, 2 hours and 24 hours. Next 4 liters of untreated deionized water were stirred on a hot plate at $37-40^{\circ} \mathrm{C}$. Dissolved oxygen was measured at initial, 30 minutes, 1 and 2 hours.

The length of helium sparging was tested. It had been noted in previous work that helium sparging lowered the dissolved oxygen level well below the desired equilibrium state. This experiment was to determine the length of time required for helium sparging to reduce the dissolved oxygen level to the experimentally determined equilib- rium level and below. Two liters of untreated deionized water were helium sparged and the dissolved oxygen was measured at 30 seconds, 1 minute, 2 minutes, 15 minutes and 20 minutes.

The effect of sonication/vacuum to deaerate 2 liters of untreated deionized water was measured. House vacuum $(\sim 27 \mathrm{in} \mathrm{Hg})$ and a bench top sonicator were used for up to 10 minutes and the level of dissolved oxygen was determined.

After determining the dissolved oxygen levels resulting from the different deaeration techniques, the effect on dissolution was demonstrated. Six vessels were filled with either $500 \mathrm{~mL}$ or $900 \mathrm{~mL}$ of untreated deionized water and brought to $37^{\circ} \mathrm{C}$. Six USP prednisone calibrator tablets were inserted and stirred at $50 \mathrm{rpm}$. (Apparatus 2). Samples were taken at 30 minutes and assayed against standards. Six additional tablets were inserted in gas permeable membrane media and then assayed, as were six tablets in helium sparged ( 2 minutes) media. This experiment was repeated with six USP Salicylic Acid calibrator tablets. Again, samples were taken at 30 minutes and assayed.

\section{Results and Discussion}

In order to study deaeration of dissolution media as one of the factors affecting dissolution, the dissolved oxygen levels were measured for media prepared under various experimental conditions. The Orion Model \#830 Dissolved Oxygen meter was used to monitor dissolved oxygen levels. The meter was calibrated electronically according to the manufacturer's specifications. Some variability was noted for measurements made on different days. Day-today variability of the dissolved oxygen level of the water had to be taken into account. Measurements by scientists in different laboratories were also considered. Therefore, a range of $\mathrm{mg}$ dissolved oxygen/L was allowed for expected variability among different days, laboratories and scientists.

Through measurements of dissolved oxygen using the oxygen meter, it was determined that for water for dissolution, the USP method of deaeration produces an average level of dissolved oxygen of $4.8 \mathrm{mg} / \mathrm{L}$. The gas permeable membrane system produced a comparable level of dissolved oxygen of $5.0 \mathrm{mg} / \mathrm{L}$ (Table 1 ).

Heating and stirring of media on a dissolution bath was examined. Heating and stirring can produce comparable levels of dissolved oxygen compared to the USP and gas permeable membrane deaeration procedures (Table 1). These experiments also confirmed that low level deaeration ( $<1.0 \mathrm{mg}$ dissolved oxygen/L) such as achieved by helium sparging, and aerated media ( $>8 \mathrm{mg} / \mathrm{L}$ ) will both adjust toward this equilibrium level while in the dissolution bath (Figure 1). 


\section{Table 1}

\begin{tabular}{|ccccccc|}
\hline time & He/20-1 & He/20-2 & GasPermMem1 & GasPermMem2 & Untreated 1 & Untreated 2 \\
\hline $\mathbf{0}$ & 1.01 & 0.95 & 5.04 & 5.01 & 18.2 & 11.9 \\
\hline $\mathbf{0 . 5}$ & 2.17 & 2.17 & 4.76 & 4.44 & 9.67 & 11.33 \\
\hline $\mathbf{1}$ & 2.95 & 3.12 & 4.9 & 4.92 & 8.72 & 9.54 \\
\hline $\mathbf{1 . 5}$ & 3.56 & 3.34 & 4.98 & 4.98 & 8.25 & 8.62 \\
\hline $\mathbf{2}$ & 3.84 & 3.88 & 6 & 5.86 & 5.83 & 8.31 \\
\hline $\mathbf{5 . 5}$ & 5.54 & 5.23 & 5.36 & 5.35 & 5.68 \\
\hline
\end{tabular}

\section{Dissolved Oxygen $900 \mathrm{ml}, 37^{\circ} \mathrm{C}, 50 \mathrm{rpm}$ Paddles}

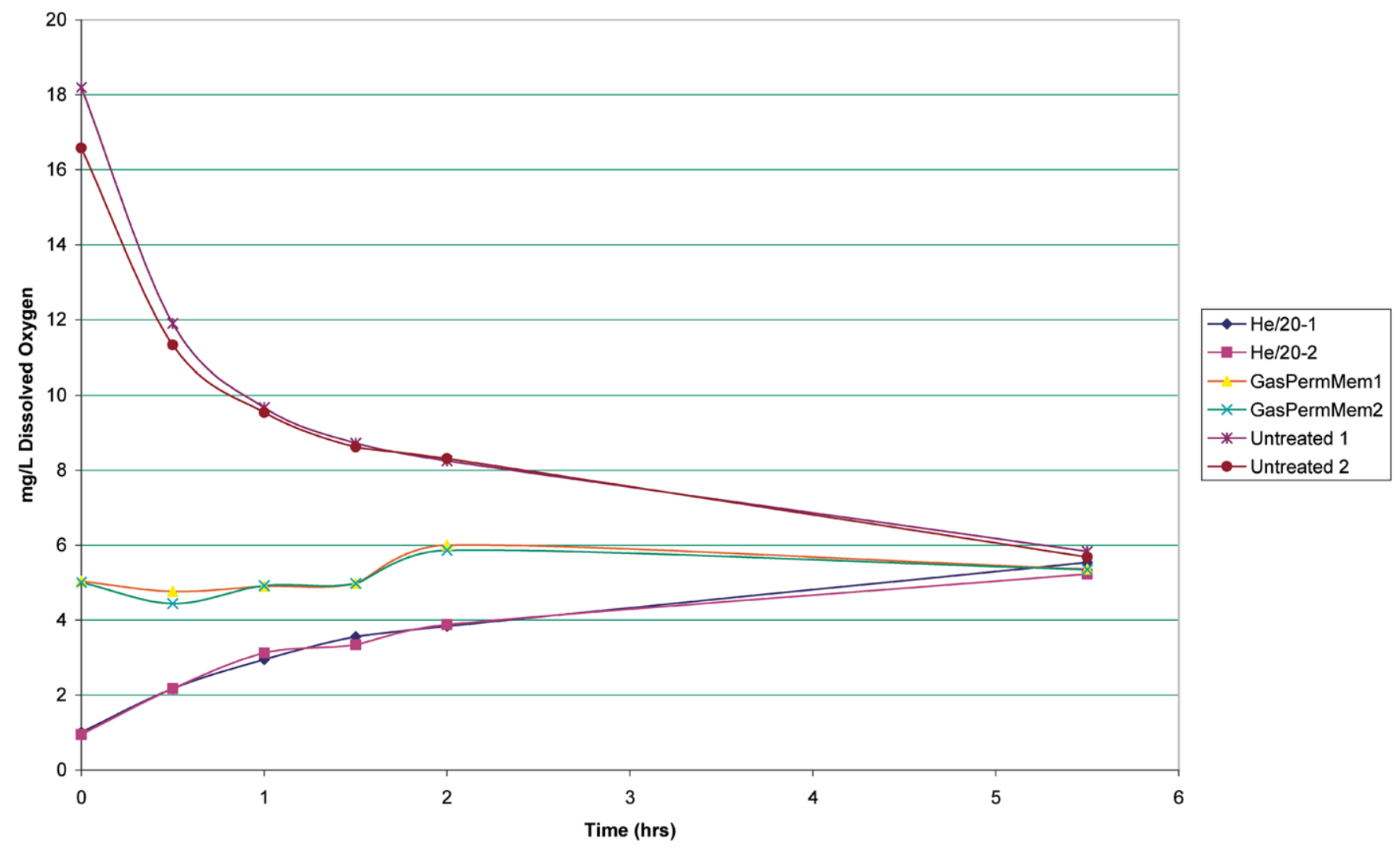

Figure 1

In order to establish at what level equilibrium occurs at $37^{\circ} \mathrm{C}$, experiments were conducted over a 24-hour period, and again over 5.5 hours. Dissolution vessels were filled with low, mid-level and high-level amounts of dissolved air media. The dissolution vessels of helium sparged, gas permeable membrane and untreated deionized water respectively, were maintained at $37^{\circ} \mathrm{C}$ and stirred at 50 rpm by paddle. The 24-hour measurement resulted in an equilibrium level of $5.5 \mathrm{mg}$ dissolved oxygen/L. The exper- iment was repeated and measurements were taken at shorter time intervals until equilibrium was attained. The resulting measurements indicated that dissolved oxygen equilibrium was achieved by 5.5 hours (Figure 1). The 24and 5.5-hour experiments indicated that all media migrated to the same point of dissolved oxygen over time, regardless of the starting level. The media with an initial reading of $5 \mathrm{mg}$ dissolved oxygen/L showed little change over time, and therefore would be regarded as at equilib- 


\section{Table 2}

\begin{tabular}{|lc|}
\hline & Pred_500ml \\
\hline He/20Min & 38.4 \\
\hline He/2Min & 35.6 \\
\hline USP & 33.6 \\
\hline GasPermMem & 34.7 \\
\hline Untreated & 78.3 \\
\hline
\end{tabular}

USP Prednisone Tablets in $500 \mathrm{~mL}$

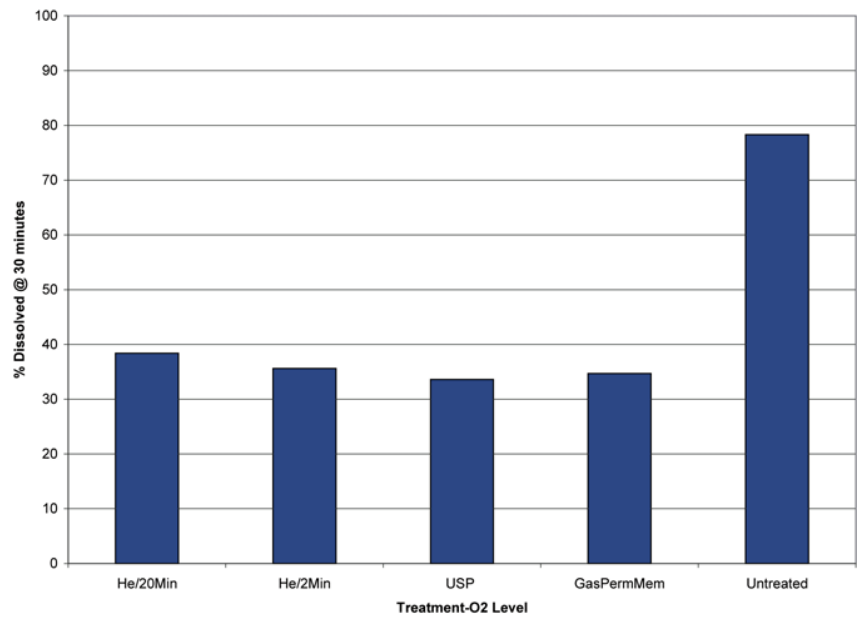

Figure 2

rium throughout the dissolution process. USP-equivalent methods of deaeration produced the equilibrated media most consistently. Dissolved oxygen equilibrium was experimentally determined to be $5.5 \mathrm{mg} / \mathrm{L}$ at $37^{\circ} \mathrm{C}, 50 \mathrm{rpm}$. Combining the equilibrium level with the oxygen meter and lab variability resulted in an acceptable range of 4-7 mg dissolved oxygen/L of deaerated media.

Helium sparging produced USP-equivalent deaerated media (3), but was difficult to control. Too little sparging and the dissolved oxygen level was still high, too much sparging and the dissolved oxygen level was too low.

Vacuum sonication of the media, did not produce desired results in the time allotted. The dissolved oxygen level did not reach the $5.5 \mathrm{mg} / \mathrm{L}$ level. Additional time and/or stronger sonication would have produced equivalent media; however, the use of extended vacuum on glass containers was a safety concern.

When deaerating by heating, the possible effects of carbon dioxide should be considered. Cooling water has a strong affinity for carbon dioxide, which can affect the $\mathrm{pH}$ of poorly buffered media (4). USP has indicated that allowing media to sit in the dissolution vessels while stirring may not be a suitable means of deaerating and believe that air is actually reintroduced by stirring (5). In

\section{Table 3}

\begin{tabular}{|lc|}
\hline & Pred in $\mathbf{9 0 0} \mathbf{~ m l}$ \\
\hline He/20Min & 59.4 \\
\hline He/2Min & 54.1 \\
\hline USP & 53.9 \\
\hline GasPermMem & 53.6 \\
\hline Untreated & 97.2 \\
\hline
\end{tabular}

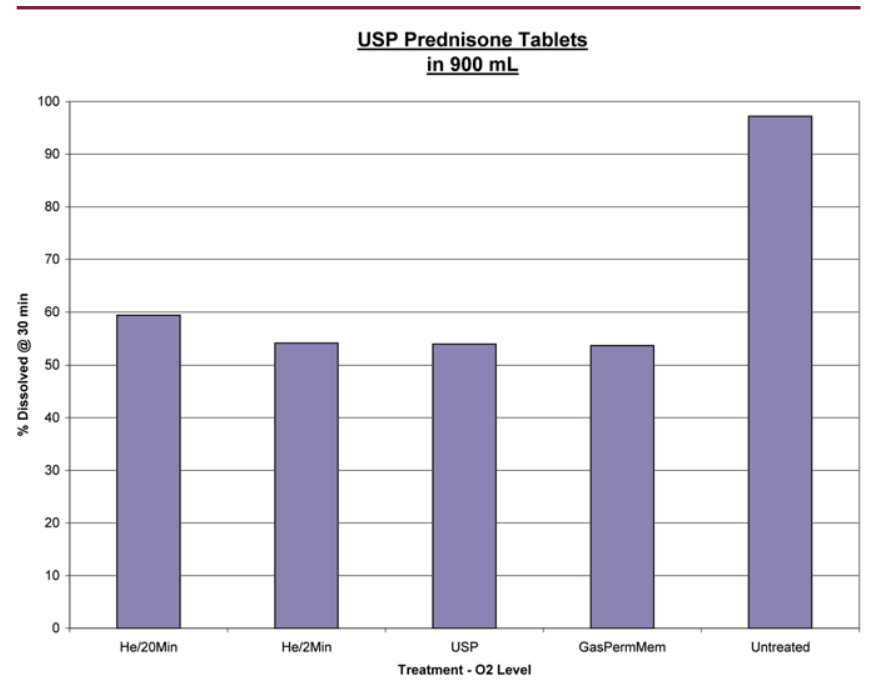

Figure 3

the current experiments, an increase of dissolved oxygen content was observed in media deaerated below the equilibrium level, with no stirring of the media. Testing also indicated that heating at $37^{\circ} \mathrm{C}$ and stirring at $50 \mathrm{rpm}$ caused the media to adjust to an equilibrated state of dissolved oxygen at approximately 5-6 mg/L (Figure 1). Although heating on a hot plate/stirrer could produce the same results, the temperature and stir speed are difficult to control. Too high a stir speed can cause additional air to be introduced, and stirring on hot plates for extended periods of time raises safety issues. Optimum deaeration should then be performed at temperatures close to the target temperature (i.e. $37.5^{\circ} \mathrm{C}$ ). This is the most consistent means to achieve the desired level of deaeration and still avoid absorption of carbon dioxide, maintaining the $\mathrm{pH}$ of the media.

To determine the effect of deaeration on dissolution, USP Prednisone calibrator tablets were tested, utilizing media at the different dissolved oxygen levels. These were compared to results generated in media prepared with the USP method, which averaged $34 \%$ dissolved at 30 minutes (Table 2). Thirty-six USP Prednisone tablets were tested in media prepared by the gas permeable membrane apparatus ( $5 \mathrm{mg} / \mathrm{L}$ dissolved oxygen). They averaged 35\% 


\section{Table 4}

\begin{tabular}{|lc|}
\hline & Salicylic \\
\hline He/20Min & 22 \\
\hline GasPermMem & 20 \\
\hline Untreated & 22 \\
\hline
\end{tabular}

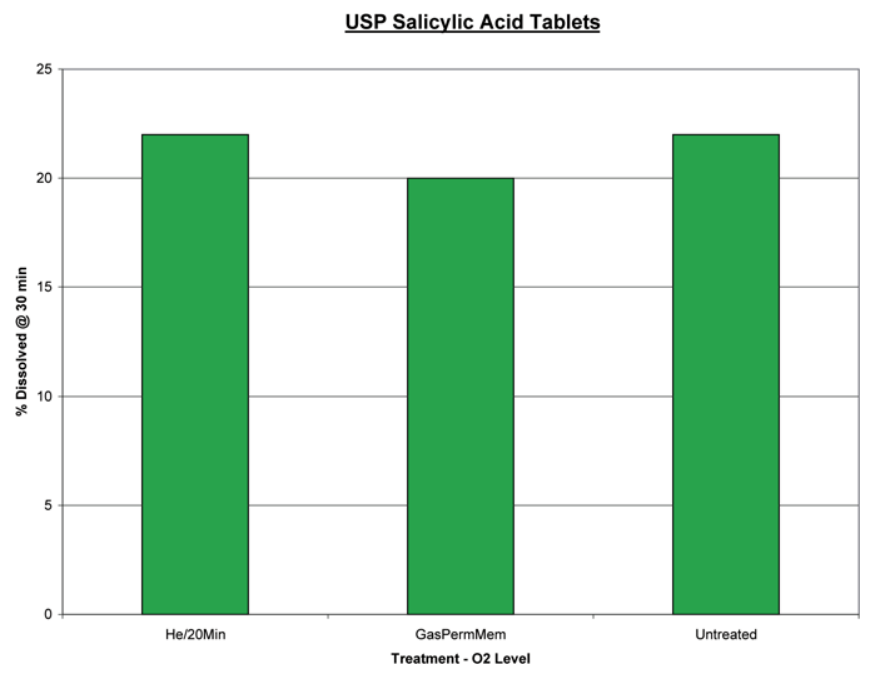

Figure 4

dissolved at 30 minutes in $500 \mathrm{~mL}$ of media. Six tablets were tested in media helium sparged for 2 minutes $(\sim 2$ $\mathrm{mg} / \mathrm{L}$ dissolved oxygen). The average was $36 \%$ dissolved at 30 minutes. When six tablets were tested in media helium sparged for 20 minutes ( $<1 \mathrm{mg} / \mathrm{L}$ dissolved oxygen), the average rose to $38 \%$ dissolved at 30 minutes. Six tablets tested in untreated deionized water media $(>8 \mathrm{mg} / \mathrm{L}$ dissolved oxygen) averaged $78 \%$ at 30 minutes (Figure 2).

USP Prednisone calibrator tablets ( 6 each) were also tested in $900 \mathrm{~mL}$ of helium sparged media (2 minutes), gas permeable membrane and untreated deionized water media. These were also compared to results generated in media prepared by the USP method, which averaged 54\% dissolved (Table 3 ). This batch produced results of $54 \%$ for 2 minute helium sparged, $59 \%$ for 20 minute helium sparged, $54 \%$ for gas permeable membrane and $97 \%$ for the untreated deionized water media (Figure 3 ). While the increase in volume of media apparently increased the solubility of prednisone, the difference between the 20 minute helium sparged and gas permeable membrane media results increased to over $5 \%$.

USP Salicylic Acid tablets were much less susceptible to the level of dissolved oxygen. Helium sparging averaged $22 \%$ dissolved at 30 minutes in $900 \mathrm{~mL}$ of media (Table 4). Gas permeable membrane-prepared media averaged 20\% dissolved. Non-deaerated media averaged $22 \%$ dissolved (Figure 4).
For the USP Prednisone calibrator tablets, sparging and using the gas permeable membrane produced acceptable results of 59 and $54 \%$ dissolved respectively, while untreated deionized water media results were $97 \%$ dissolved (Figure 3). For the Salicylic Acid calibrator tablets, all media produced results within the acceptable range (17-26\%).

The test results of the Prednisone and Salicylic Acid calibrator tablets indicate that the effect of dissolved oxygen on dissolution is product dependent. The assay differences seen, based on the levels of dissolved oxygen, are enough that there could be issues using non-deaerated dissolution media for formulations that are sensitive to the level of dissolved oxygen. For formulations that are not sensitive, issues might still arise when transferring dissolution methods between labs. There could also be an issue between consecutive time points during stability studies. The differences are enough that the level of deaeration should be considered for dissolution testing.

\section{Conclusions}

Deaeration of dissolution media, as measured by the level of dissolved oxygen, can have an effect on the dissolution of solid dosage formulations. Different techniques of deaeration will result in differing levels of dissolved oxygen. Recommended techniques result in dissolved oxygen between 4 and $7 \mathrm{mg} / \mathrm{L}$, equivalent to the USPrecommended technique.

The gas permeable membrane method routinely delivers media in the desired dissolved oxygen range. Helium sparging may deliver media in the desired range, but is difficult to control. Heating and stirring may also deliver media in the desired range but is unreliable. Untreated media is too variable.

The level of deaeration may or may not have an effect on the dissolution profile of a particular formulation or product. Potential effects will depend on the physical and chemical characteristics of each formulation.

The level of deaeration and its effect on dissolution will also depend on the testing laboratory and the water treatment used in the laboratory. It is important to have an understanding of the native dissolved oxygen level in the untreated water.

The goal of developing a dissolution method for pharmaceutical solid dosage forms is ultimately to produce a reliable test that will give reproducible results. Ruggedness and reproducibility are critical, and may ultimately be affected if the dissolution media conditions cannot be reproduced. To prevent changes in the dissolution media, and the test results, it is necessary to produce media that is at equilibrium before and during the dissolution test. It is critical to maintain and control dissolution parameters 
such as temperature, paddle speed, sampling probe depth and so on. The level of deaeration should be added to that list of parameters.

\section{References}

1. USP 27, 2004: Physical Tests, <711> Dissolution, "Dissolution Medium", Footnote 3, p 2304.

2. Qureshi, S.A., McGilveray, I.J.,"Impact of Different Deaeration Methods on the USP Dissolution Apparatus Suitability Test Criteria"; pg4-138; Pharmacopeial Forum 20 (6), 8565-8566, 1994.
3. Degenhardt, O.S., Waters, B., Toltl, N.P., et al, "Comparison of the Effectiveness of Various Deaeration Techniques." Dissolution Technologies, 11 (1, February) 6-11, 2004

4. Gray, V.A., Hubert, B.B., Krasowski, J.A., "Calibration of Dissolution Apparatus 1 and 2 - What to Do When Your Equipment Fails," Pharmacopeial Forum 20 (6), 8571-8573, 1994.

5. Lindauer, R.F., “USP Dissolution Calibrator tablets - Is It Time to Reduce the Amount of Testing Required to Calibrate Apparatus 1 and 2?" Pharmacopeial Forum 